escape infection was one who was wearing one of the vests above described.

The experiments and observations of Kinloch and others have also shown that naphthalene possesses a high value in killing and warding off pediculi; its use for this purpose is, of course, not new. The value of sulphur, which one thought was established, has, however, been disputed. Nevertheless I have retained it, for trvo reasons. In the first place I hoped it might prevent the generalized spread of scabies, another parasitic disease which has been prevalent at home and abroad; and there is some evidence in favour of this view. In the second place, I am not yet consinced that sulphur is quite innocuous to the pediculus. This conclusion caunot, for instance, be drawn from the fact that the louse can remain alive on sulphur ointment. It is only when sulphur is changed into sulphides that it becomes active; and, at ordinary temperatures, the con centration of vapour of sulphide over sulphur ointrent niust be small. When, however, sulphur in the state of tine division in which it is precipitated from benzol is left in contact with the skin and therefore at body temperature, the vapour of sulphicle, partly prevented from escape by surrounding garments, may reach a concentration sufficiently ligh to be injurious to the pediculus.

Dipping the garment in a solution of sulphur and naphthalene in benzol has advantages over merely sprinkling the garment with the same substances in powder (].) because the clistribution of the powder is uniform and universal, (2) because, being impreguated in the fibre of the garment, it is longer retained, and (3) because the treatinent is not left to the soldier himself, who receives the garment already treated. I may add au extract from a letter recently received from an officer in France who has taken much trouble to report on the efficacy of these autiparasitic vests.

The shirts are doing good work and there is guite a demand for them. 'The billets we occupy at present are not very clean and conseguently scabies is guite common. For scabies the shirts are excellent. For lice they do the work, but in some cases take time before they actually kill the lice. For sono days the latter lie dormant on the shirts before they die sons man showed me a shirt with over 200 dead on it. 'This is man showed me a shirt with

From this letter and other's it may be gathered that a man who receives a prophylactic vest tends to keep it in reserve until he is actually infected. With a restricted distribution of the garments this is unavoidable. Indeed it may be suggested, to prevent disappointment, that there is probably no practical method possible which will ensure that a wan, sufticiently exposed to infection, wili never be bitten by a lonse. Also it is obvious that such a proply lactic as liere suggested has a time limit, and nnless a man has a continuous supply for use he will be reinfected. If, however, all the individuals of a group of soldiers living in close assuciation were systematícally provided with such a prophylactic, it might so far torvards solving the problem of pediculosis and scabies among them. 'The problem involves not merely infection of the individual but his infecting, and being infected by, his comrades. A complete solution is possible only when propliylaxis applies to them all. Moreorer, the infection of bedding, etc., is a further problem whieh can only be partly attacked by depriving the parasites of possible hosts.

The evidence upon which this note is based is not the result of direct obserration, and suffers from all the defects that such want involves. On the othcr land, I hare no reason to suppose that repor ts received stcadily since June, 1915, can all be misleading, and I think the method is worthy of a more extended trial. I should suggest, there. fore, that it would be a valuable experipent to provide all the members of an associated group of soldiers with antiparasitic vests and to observe the resnlt in regard to the prevention of pediculosis and sc:abies. It has not been found possible to perform such an cxperiment by private effort directed at liome.

It is possible that some such device might find its uses in civil practice. It is at once a method of prevention and treatment. For example, my friend Captain Girdlestone hias applied the vests in patients anderneath plaster jackets. In the cases in which he has so far used these vests there have been no cases of pediculosis, and no skin irritation has been produced.

\section{PRELIMINARY NOTE ON A NEW TREATMENT OF BRONCHIAL ASTHMA.}

\author{
A. G. AULD, M.D., \\ LONDON.
}

THrs communication refers to a particular treatment which I have recently been applying to certain selected cases of bronchial asthma. The patients have been free from all disease, other than the bronchial affection, and although move or less emphysema and bronchial catarrh have been present, they have nut been of a high degree, or such as to create dyspnoea in the intervals of freedom (more or less) from the attacks.

I way be permitted, first of all, to malie reference to the view as to the nature of bronchial asthma which $I$ sub. mitted in the course of a lecture on this subject in 1908.1 It was to the effect that the asthmatic attack is a reaction on the part of the lungs to a toxic substance " either of distinctly pathological origin, or else a product of normal metabolism which gradually accumulates in the blood." In the following year Auer and Lewis, ${ }^{2}$ of the Rockefeller Institute, showed that the lung of the guinea-pig in anaphylaxis presented conditions identical with those of bronchial asthma. They found the pulmonary distension to be due to impriscnment of the air in the alveoli from an intense brouchiolar constriction which was exclusively of peripheral origin. The symptoms could -be relieved or averted by atropine. The anaphylactic nature of bronchial astluma has since then been expounded by Meltzer and many others, though the particular protein substance responsible is unlmown. The various authorities also regard hay fever as an anaphylactic condition. Anaphy. laxis does not attack the bronchial muscle in all animals, but it does so in man.

There are one or two points concerning anaphylaxis which require to be stated. It is generally believed that the reaction is one of extreme delicacy and very specific. So it is, but under certain conditions this specificity dis. appears, as has been clearly proved by the work of Dale, ${ }^{3}$ who showed that if a guinea-pig be sensitized to several antigens simultaneously, and an anaphylactic reaction be subsequently induced by a fairly large dose of one of the antigens, the animal thereby may be made refractory to the oileer antigens. Again, he found that if an animal be itmmunized to an antigen by giving a certain number of doses subcutaneously at short intervals, the animal as a whole being thus rendered immume, yet the excised uterus, or other susceptible organ, remains sensitive, not only to the antige'n, but also to other substances akin to the antigen - for instance, to sheep's serum, where horse's sertum lias cmployed for immunizing. As the organ beconses descusitized to a second dose of sheep's serum the genuine nature of the auaphylaxis is proved. In like manner Fraus, Doerr, and other's showed that animals sensitized to their own leus protein werre susceptible to lens. protein in general. The fact that an animal may be itself insensitive while its excised organ remains sensitive is explained by the nentralization of the antigen in the blood by antibudies before it has had time to attach itself to the fixed cells of the organ. "Certain of the above facts recall the Ablerhalden reaction.

Just as animals may be sensitized witli theiv own lens protein, so autosensitization may talic place in the case of brouchial as'luma. Anotlici "possible instance of auto. sensitization, according to Rosenau aud Anderson, is eclanipsia, due to placental protein.

In applying the foregoing considerations to the condition of bronchial astluma, it ivas uecessary to select a substance for the purpose of immunizing, which, if it did not contain the actual anaphylactic protein poison; nevertheless might contain one nearly akin to it. This condition appeared to be fulfilled in the casse of peptone. Certain experiments of Biedl and Lipius were of great inlerest in this comnexion.4 They obtained bronchial spasm in guiveapigs after the administration of Witte peptone, and they claim to hare produced an anti-anaphylaxis in serumseusitized dogs by means of the same agent. 'Tley hold the Witte peptone to be identical with the anaphylactio poison.

The meihot I liave been enıloying is immunization by the subcutaneous injection of a water solution of peptons. 
Not being able to obtain Witte peptone, that of Armour was used. Other kinds may be as efficacious, but it is necessary to remember that the various brands of peptone on the market may differ considerably in composition and thus affect the results. To begin with, $\frac{1}{3}$ gram of peptone dissolved in about 5 c.cm. distilled water at blood heat is injected at an interval of three or four days during the first week. The next week two injections, each of $\frac{2}{3}$ gram, are similarly given, and in the third week two injections of 1 gram in 7 to $10 \mathrm{cccm}$. water. In certain cases this may be sufficient; severer cases may require 1 gram weekly or bi-weekly for three weeks more. No apparent constitutional reaction follows, and, properly carried out, there should be little or no local reaction.

In the limited number of cases tried the results have surpassed expectation. In several cases of moderate astlıma the symptoms have become perfectly quiescent, while others have greatly benefited. In one case three months have elapsed without any recurrence. Sometimes the effect is very rapid, the patient experiencing relief after one injection. Where attacks of great severity occurred every two or three months, a few weeks' treatment beforehand has caused the attack to abort. I hope to submit further details in a future communication.

References.
1 British Medical Joturnal, 1908 , vol. ii. 2 Journ. Amer. Med. Assoc., vol. liii, 1909, p. 453. 3, Journ. Pharm. and Exp. Therap., vol. iv, 1912, p, 167. "Wien. klin. Woch., No. 11.

\section{fftemoration:}

\section{MEDICAL, SURGICAL, OBSTE'TRICAL. \\ THE CAUSE OF DEATH IN ACE'TE PNEUMONIA.}

What is the cause of death in acute pneumonia? This is a question I have often asked, and the usual reply is"toxaemia" (that is, the effects of toxaemia).

I have often wondered why all symptoms suddenly disappear, respirations, pulse, and temperature become normal, whilst for a time the physical signs continue more or less the same. On asking why the symptoms disappear the reply is that the "toxaemia" is overcome.

The fact that the consolidation is still present after all synaptoms have disappeared, and the sudden appearance of symptoms before the physical signs, seems to show clearly that the rapidity of respiration, etc.; is not due to the local condition. The increased action of the lieart in the early stage must be due, like the respiratory change, to stimulation of the nerve centres controlling these organs.

The question, How are these centres "stimulated"? sug gests itself, and the answer again is, through " toxaemia" then to narrow the subject further one asks, through what channel? The answer does not appear so easy, for the channel of the "toxaemia," general or local, must be dis. covered, since upon that answer, it seems to me, treatment greatly depends.

Are all these symptoms which suddenly disappear, leaving the local physical signs still present, due to a sudden neutralizing of the pneumococcus toxins this seems improbable), or are they due to something else, and if so, what? Is it cessation of absorption due to sudden decrease of intraspinal pressure?

In the old books on the treatment of pneumonia bleeding was often advocated, to be frequently repeated, with the result that the patient often died. May not the underlying motive for the bleeding, lowever, have been to reduce pressure with the object of preventing exudation? And though the means of attaining the object aimed at appear to have been ineffective, the amelioration of sym ptoms which followed for a time was probably due to a temporary diminution of absorption of toxins, possibly through diminished intraspinal pressure.

Physicians of the last generation were certainly, as observers of clinical symptoms, equal to the present ones, allowing for the absence of to-day's scientific knowledge; and though they were often wrong, there was generally a substratum of truth to thieir procedures, and bleeding in acute pneumonia may be an illustration of a practical truth.
If the symptoms are due to a poisoning of the nerve centre, it may be assumed, reasoning by analogy as in the case of spinal meningitis, that the toxin is absorbed from the spinal canal, probably under pressure, as in that disease. If it is absorbed from the spinal canal under pressure, then decrease of pressure would lead to decrease of absorption and gradual or more or less sudden dis. appearance of the symptoms.

If decrease of pressure leads to such a desirable result, why not adopt the method of tapping the theca as in the treatment of spinal meningitis, and by so doing follow a rational metliod of treatment? It could do no harm. No surgeon would rely upon using autogenous vaccine made from the organismas of a septic abscess without draining the abscess and so preventing fresh supplies reaching the economy. Clearly the indication is to prevent absorption as far as possible, and nature will do the rest.

If the poison is, as I am inclined to think, absorbed by the nerve centres under pressure, thus producing the symptoms, then draining these centres through the spinal canal seems to me rational treatment; more especially because it is known that intraspinal pressure is frequently, if not always, increased in acute pneumonia, and because meningitis is, I believe, found in a very laige percentage of fatal cases.

Tid worth Military Hospital.

H. Y. Drew, F.R.C.S. Captain R.A.M.C.

ATROPINE IN EYE WORK.

THE case reported below illustrates one of the many baa tricks atropine is apt to play in eye work. No one will condemn this very valuable drug on account of its tricks, but we must bear them in mind when using it. Perhaps more mischief arises from its use in unsuspected high tension than from anything else. Again, all are familiar with its habit of causing irritation of the conjunctiva with oedema (usually in unlealthy eyes, as witness its associa. tion with sympathetic ophthalmia). Further, not long ago I ordered the ointment of atropine sulphate (B.P.) for insertion into the conjunctival sac of a child aged about 6 years, preparatory to estimation of the error of refraction. Within two hours of the first application and early in the day, the child fell into a deep, almost comatose, sleep, lasting nearly twenty-four hours. Again, there are cases of prolonged paralysis of accommodation after atropine, and at least one instance of lasting paralysis has been brought to my notice. In cataract extractions the mere use of one drop of liquor atropinae sulphatis will sometimes evoke an attack of temporary maniacal insanity.

The special case I wish to record, however, is that of an alarming change in cardiac and respiratory action which came over the patient twelve hours after such a drop had been used after extraction.

The patient was aged 71 years, and very nervous. About twelye hours after the operation, having felt sick and faint for some time, she complained of difficulty in swallowing, and became dyspnoeic. She was very pallid and cold. The front of the neck was swollen and puffy, especially on the side of the eye operated on. The other pupil was wide and reacted feebly. The pulse was 90 , scarcely perceptible, and a little irregular. The breathing was of the cheyne-Stokes type with short rest intervals. The patient was collapsed and gave every appear. ance of dring. Speech was feeble and indistinct, and swallow. ing ing almost impossible. Strychnine was administered hypodermically,gr. Ir Fortunately within an hour the breathing improved with the rightly or wrongly, was not givei on account of the respiratory coudition.

Horatio Matthews, M.D.,

Honorary Ophthalmic Surgeon to the Eastbourne Ese Intiruary

\section{AFTER-HISTORY OF THREE CASES OF} IN'TESTINAL OBS'TRUCTION.

CASE I was a woman of 40 , who refused operation till late, with gangrenous intussusception and polypus. Resection performed and lateral anastomosis with third size Murphy's button, owing to contracted state of distal guto This woman died five years later at an asylum, of meningitis. A post-mortem examination was unfortunately refused. During the five years she had no signs or symptoms of stricture. 